This item was submitted to Loughborough's Research Repository by the author.

Items in Figshare are protected by copyright, with all rights reserved, unless otherwise indicated.

\title{
Participatory ergonomics: co-developing interventions to reduce the risk of musculoskeletal symptoms in business drivers
}

\section{PLEASE CITE THE PUBLISHED VERSION}

http://dx.doi.org/10.1080/00140139.2012.737028

\section{PUBLISHER}

(C) Taylor \& Francis

\section{VERSION}

AM (Accepted Manuscript)

\section{LICENCE}

CC BY-NC-ND 4.0

\section{REPOSITORY RECORD}

Gyi, Diane E., Katherine J.C. Sang, and Cheryl Haslam. 2019. "Participatory Ergonomics: Co-developing Interventions to Reduce the Risk of Musculoskeletal Symptoms in Business Drivers". figshare. https://hdl.handle.net/2134/11403. 
Gyi D, Sang K and Haslam C (2012). Participatory ergonomics: co-developing interventions to reduce the risk of musculoskeletal symptoms in business drivers. Ergonomics, 56(1), 45-58.

\section{Participatory ergonomics: co-developing interventions to reduce the risk of musculoskeletal symptoms in business drivers}

Diane Gyi ${ }^{\mathrm{a}}$, Katherine Sang ${ }^{\mathrm{b}}$ and Cheryl Haslam ${ }^{\mathrm{c}}$

${ }^{a}$ Loughborough Design School, Loughborough University, Loughborough, Leicestershire, LE11 3TU (01509 223043, d.e.gyi@lboro.ac.uk)

${ }^{b}$ CRoWW, School of Management and Languages, Heriot-Watt University, Edinburgh, Scotland, EH14 4AS (0131 451 4208, k.sang@hw.ac.uk)

${ }^{\mathrm{c}}$ Work and Health Research Centre, School of Sports Exercise and Health Sciences, Loughborough University, Loughborough, Leicestershire, LE11 3TU. (01509 223086, c.o.haslam@lboro.ac.uk)

Corresponding author:

Dr Diane Gyi

Loughborough Design School Loughborough University Leicestershire

UK LE11 3TU

01509223043

d.e.gyi@lboro.ac.uk 


\title{
Participatory ergonomics: co-developing interventions to reduce the risk of musculoskeletal symptoms in business drivers
}

\begin{abstract}
The participatory process within four case study organisations with a target population of high mileage business drivers is described. The aim was to work with drivers and their managers to co-develop intervention activities to raise awareness of musculoskeletal health in drivers, including use of the car as a mobile office and manual handling from the car. Train-the-trainer sessions were delivered in each organisation, along with the co-production of training materials. The effectiveness of these activities were evaluated using three sources of data, post intervention questionnaires, interviews with organisation 'champions' and observations from the research team's diaries. The approach raised management awareness of the risks to drivers and was successful in affecting change and as such, participatory research should consider the early stages of a project as part of any intervention activities. The research team also reflect on conducting applied longitudinal research in the field.
\end{abstract}

\section{Practitioner Summary (50 words)}

Raising awareness of the risks of MSDs in drivers who work from their vehicle is important. This paper reflects on research in the field and provides guidance on the participatory process and evaluating intervention activities. The participatory process was successful in affecting change at management level.

Keywords: participatory ergonomics; musculoskeletal symptoms, occupational health, driving.

\section{Introduction}

Approaches which engage the end user in the process of the development and implementation of ergonomics interventions can be viewed as 'participatory' (Gjessing et al., 1994). Participatory approaches to reducing work related musculoskeletal disorders (MSDs) have received considerable attention in the literature (e.g. van Eerd, et al., 2010). Tailored interventions, whereby they match employees' readiness to change 
(Prochaska et al., 2001) are significantly more effective in reducing MSD symptoms than standard interventions in a wide range of industries, including baggage handling, call centres and delivery/logistics (Whysall et al., 2005, 2006a, 2006b). The involvement of end users in the development of ergonomics interventions is a key aspect of their success (Hignett, 2003). Workers have a detailed understanding of their job and in many instances are able to provide useful input to solving ergonomics problems (Hess et al., 2004). Additionally, involving workers helps to build trust and commitment which may result in increased job satisfaction and improved performance (Brown, 2002).

Musculoskeletal disorders (MSDs) are the leading cause of work related illness and the second most frequently cited cause of sickness absence after the common cold (HSE, 2010). There is evidence that business drivers are particularly susceptible, for example, those who drive for 20 hours or more per week are more likely to take sick leave (Porter and Gyi, 2002). Reasons suggested for this include seat vibration (Basri and Griffin, 2012), constrained postures, manual handling risks and prolonged sitting (Porter and Gyi, 2002). Use of the car as a mobile office may also be problematic (Flyte, 2000; Sang et al., 2010a). Business drivers therefore represent a group which may benefit from efforts to reduce their risk of MSDs.

The broader management literature has begun to emphasise the importance of 'bottom-up' approaches to organisational change (Buckland, 2009). More precisely, these may be effective as they move beyond confirming to managers what they already know (Haslam, et al., 2003). Bottom-up approaches drive change from the lower levels of organisational hierarchies and therefore any intervention activities are developed with those who will be implementing them. Such approaches are guided by the understanding that workers are able to provide a significant contribution to an intervention, and impact its success (Hess et al., 2004). Participatory ergonomics can be defined as 'practical ergonomics with participation of the necessary actors in problem solving' (Kourinka, 1997, p. 268). This is an important definition, since it allows for the involvement of all actors in the development and implementation of interventions, including those in senior management positions who often have a wider understanding of the problem.

The principles of the co-operative enquiry model as proposed by Reason (1994) have informed participatory ergonomics studies (Hess et al., 2004). The model comprises four phases: 
(1) researchers and participants agree on the area which will be studied

(2) researchers and participants work together to identify an initial change in workplace practice which will aim to reduce an identified risk

(3) participants implement the proposed intervention

(4) researchers and participants work together to develop, implement and assess the efficacy of the participant initiated intervention

This approach allows for recognition of the expertise of both the researchers and the participants or workers (Hess et al., 2004). It allows a research team to make suggestions on how to solve an identified problem, and participants can provide feedback. A key component of an intervention's success is the degree to which it is accepted by all participants, i.e. both workers and their employers (Brown, 2002).

Wilson (1995) presented an example of a participatory ergonomics intervention in a crane control room redesign which successfully resulted in a process of continuous improvement, i.e. the employers continued to work with other stakeholders to make changes to their workplace. Wilson's (ibid) study followed a similar framework to that of Reason (1994) and began by scoping the problem through observations, archive analysis, questionnaires and environmental surveys. A range of ergonomics problems were identified and a problem solving group was established to develop, implement and evaluate resulting changes.

Van Eerd et al (2010) conducted a systematic review of participatory interventions, identifying key components which should be considered. They argued that it is important to ensure that teams with the appropriate members are involved in the participatory process, for example, people with expertise, i.e. workers, supervisors, specialists or advisors (either from within or outside the workplace). The responsibilities of each participant should be clearly defined and any decision making should be collaborative. The provision of ergonomics training also appears to be an important component of participatory interventions. Researchers should also be aware of the potential facilitators and barriers to any interventions (van Eerd, et al., 2010). The most commonly reported of these are support for the intervention, availability of resources, ergonomics training, team creation, communication and organisational training.

Given the apparent value of a participatory approach, the realities of conducting field research must be considered. In field studies, the research team often have very little control over organisational issues and work processes (Israel et al., 1992). This can 
result in difficulties controlling factors, such as relationships between workers and their managers, which may impede achievement of the research objectives (Rosencrance and Cook, 2000). In addition Macaulay et al (1999) have suggested that the success of a participatory approach may be hampered by a change in participants' priorities, whereby the researchers may not be able to continue to work with an organisation.

As discussed previously individuals who drive as part of their job are at increased risk of developing musculoskeletal symptoms (e.g. Sang et al, 2010a) and may be more likely to take sick leave due to such symptoms. There is a need to develop interventions which will effectively reduce the risk factors associated with working from the car and so facilitate the occupational health management of drivers. Harris et al (2003) suggest that priorities for reducing MSDs amongst business drivers should include the introduction of a robust manual handling policy for laptops and other equipment, in addition to risk assessment and a management approach which involves both the employer and the employee. They argue that interventions should emphasise training both the driver and their employer on the ergonomics risks associated with field work and that online risk assessments should be accessible to all drivers.

The extant literature has demonstrated that business drivers may be at increased risk of developing MSDs. This paper evaluates the participatory ergonomics approach in developing intervention activities for business drivers in four case study organisations. It argues that participatory processes can be useful in raising management and employee awareness of ergonomics concerns. It begins by considering the benefits of such an approach in reducing exposure to risk factors for MSDs and then describes the process in four case study organisations and the evaluator steps taken. The objectives were to:

- describe the participatory process in the development of intervention activities

- evaluate the impact of the participatory approach

- discuss the lessons learned from undertaking research of this kind.

\section{Method}

The following section describes the method adopted in for research presented in this paper which was funded by the BUPA Foundation. It begins by outlining the selection and recruitment of participating organisations. A brief description is then given of the 
project and the collection of the questionnaire survey data used to guide the participatory process.

\subsection{Initial meetings with organisations}

Organisations were selected using personal contacts of the team and snowballing techniques. Inclusion criteria were; organisations with a cohort of business drivers who drove $\geq 15,000$ miles/year or $\geq 4$ hours/day. Following discussions with 17 organisations, four were selected to take part:

(1) Multinational manufacturing company

(2) UK based utilities organisation

(3) Multinational pharmaceutical company

(4) Multinational consultancy

In order to preserve the anonymity of the participating organisations, a brief description of the context is provided. All participating organisations employed over 500 people and as such could be viewed as large businesses. Each organisation had a population of employees who drove as part of their job (rather than those who drive as their job, for example, delivery drivers). In addition, all organisations had an occupational health division and a manager who could facilitate access across the various sections of the organisation.

From the moment of first contact with each organisation, detailed research diaries were kept by the researcher documenting contact (face to face, telephone and email) with representatives of each organisation. In addition, reflections on the meetings and other activities were recorded. As stated previously, the research was guided by Reason's (1994) framework. Following email and telephone contact with potential collaborators, the first stage of the process was the initial meeting between the University research team (hereafter referred to as the research team) and key staff (Table 1). Figure 1 illustrates the generic participatory process followed in each of the participating organisations. In the initial meetings the research team provided detailed information about driving ergonomics and the scope of the research. 
Table 1. Details of the initial meetings and evaluation interviews with organisations.

\begin{tabular}{|c|c|c|c|}
\hline Organisation & Initial meetings & In attendance & Evaluation interviews \\
\hline 1 & May 2007 & $\begin{array}{l}\text { Organisation champion: } \\
\text { Occupational Health Manager }\end{array}$ & N/A \\
\hline 2 & August 2007 & $\begin{array}{l}\text { Organisation champion: } \\
\text { Health } \\
\text { and safety advisor, } \\
\text { Fleet Manager }\end{array}$ & February 2009 \\
\hline 3 & September 2007 & $\begin{array}{l}\text { Organisation champion: } \\
\text { Occupational health advisor, } \\
\text { Area sales manager, } \\
\text { Health and Safety advisor, } \\
\text { Occupational health administrator }\end{array}$ & January 2009 \\
\hline 4 & November 2007 & $\begin{array}{l}\text { Head of Health, Safety } \\
\text { and Environment }\end{array}$ & February 2009 \\
\hline
\end{tabular}

It became apparent early on in the project that communication with a large number of people and committees was required before approval was given for the project and that this process lead to early dissemination of information about the project and of driving ergonomics. Consequently, it was noted that the initial meetings were likely to constitute the start of the participatory process. In addition to securing agreement for participation, the main aims of these meetings were to:

- raise awareness of the issues associated with business driving that may affect the health of their drivers

- secure senior management commitment to the project, for example personnel resources and time to support the intervention activities

- discuss the potential value of participation with the organisations.

It was also important to have access to business drivers and other key stakeholders who would be able to inform the development of the intervention activities. Therefore, at the initial meetings each organisation appointed a 'champion' who was to be the research team's key contact. In addition to this, they were able to identify stakeholders in their organisation who were able to inform and drive the project. Each champion held expertise in either occupational health or work-related 
driving and so they had an understanding of MSD issues more generally and the specific needs of the drivers within their organisations.

\subsection{Questionnaire survey}

After agreement had been secured to participate in the project, it was necessary to understand the work tasks of the drivers that the team would be working with. An online questionnaire was distributed to selected drivers within each organisation who had been identified by organisation champions as undertaking high mileage. This questionnaire was also re-distributed at the end of the participatory process for comparison of data at two time points ( $\mathrm{T} 1$ and $\mathrm{T} 2$, Figure 1). The questionnaire itself was not part of the participatory process in that it did not provide a forum for drivers to co-development any interventions. It did however include a number of the measures to help evaluate any attitudinal and behavioural changes during the course of the study. Data included:

- Musculoskeletal symptom prevalence: Nordic Musculoskeletal Questionnaire (NMQ) (Kuorinka, 1997)

- Job Satisfaction Questionnaire (from the Michigan Organisational Questionnaire. Camman et al., 1983)

- General Health Questionnaire (GHQ 12) (Goldberg, 1972)

- Intention to Leave Scale (from the Michigan Organisational Assessment Questionnaire, Camman et al., 1983)

- Organisational Commitment Scale (Eisenberger et al., 1986)

- Driving related behaviour, for example, working from the car.

In addition, the questionnaire included an assessment of driver 'Stage of Change' with respect to MSDs which allows analysis of drivers' awareness of MSDs and the extent to which they had considered making changes to working practices (Whysall et al., 2006a, 2006b and 2007). Resulting interventions could then be tailored to meet the specific needs of drivers. The findings from the driving questions (particularly working from the car) were also used to ensure that intervention activities could be targeted at these particular behaviours. 
Figure 1. The participatory process

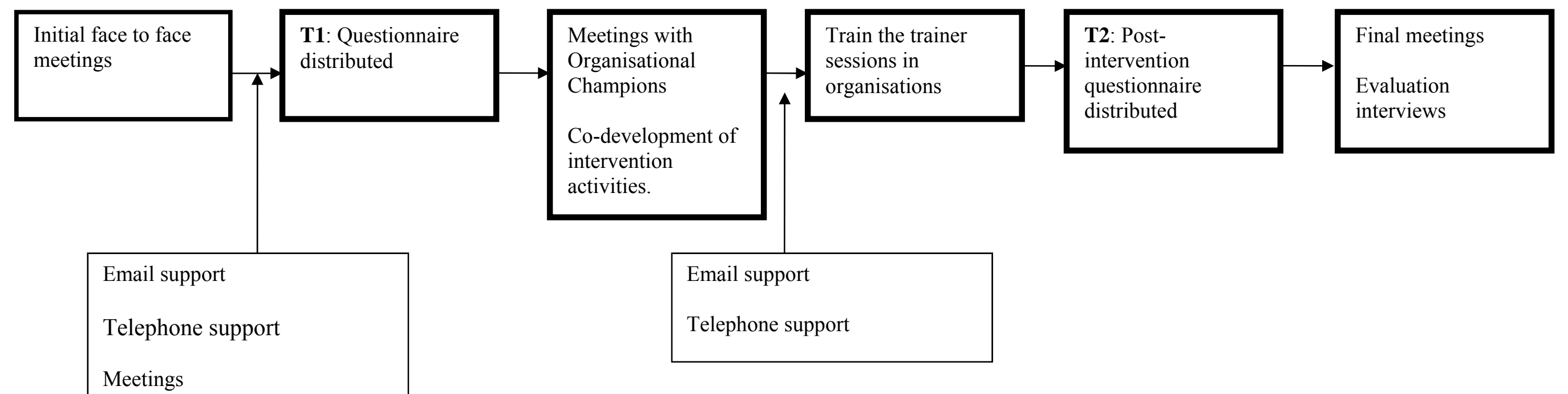




\subsection{The participatory process}

\subsubsection{In-depth interviews}

The questionnaire data provided some quantitative indicators of the tasks undertaken by the study population and of musculoskeletal symptom prevalence. To make recommendations for intervention activities, it was necessary to build an understanding of the existing structures and policies in place within each organisation and to co-develop ideas for the occupational health management of business drivers. Indepth interviews were therefore conducted with a sample of key stakeholders and also provided a forum to discuss issues which could then be raised with senior managers. These respondents were purposively sampled by the organisation champion for their knowledge of policies and practices covering:

- job details

- driving ergonomics

- occupational health management systems

- driver training

- measures for improving driver health

Interviews were transcribed verbatim and analysed using a process called Template Analysis (King, 2004).

\subsubsection{Co-development of activities}

As detailed previously, after securing agreement, questionnaires were distributed to drivers and interviews were conducted with key stakeholders. Findings from this questionnaire and the interviews were summarised and presented for discussion to senior representatives in each organisation (including the organisation 'champion'), some of whom were also high mileage business drivers. During these meetings, the intervention activities were discussed, prioritised and actions agreed. Broadly, implementation would involve 'train-the-trainer' sessions whereby the research team provided training to key members of the organisations who were responsible for training provision for business drivers. These sessions provided general training on driving ergonomics and more organisation specific information, for example, sources of help in 
the organisation. These trained personnel (managers, occupational health managers, health and safety officers and business drivers) were then able to take this knowledge to their respective organisations, with support from the research team as necessary. An online resource was put together to aid dissemination, and to provide guidance to business drivers and their employers.

\subsection{Evaluation of the participatory process}

A key element of any intervention is evaluation. Participatory processes can be evaluated in a number of ways, for example, reduction in the prevalence of musculoskeletal symptoms or an assessment of levels of awareness of ergonomics concerns and communication within organisations (Laing et al., 2005). The current study used two approaches: distribution of an online questionnaire at two time points and semi-structured interviews with key stakeholders.

\subsubsection{Questionnaire survey}

In the current project, it was intended to evaluate the intervention process through redistribution of the online questionnaire, whereby each driver acted as their own control (T1 and T2 in Figure 1). This would have enabled an analysis of the intervention's impact on individual health outcomes. However due to significant participant attrition attributed to staff turnover and clashes with other priorities, such as a new product launch, this was not possible. Also, due to financial difficulties and redundancies amongst the driving population, Organisation 1 was forced to withdraw completely towards the end of the project.

The remaining organisations gave consent for the original online questionnaire to be re-administered to the same samples of drivers. However, the small number of matched pairs within each organisation $(0 \%, 36 \%, 29 \%$ and $21 \%)$ meant that statistical analysis was not appropriate, and trends in the data only are briefly reported in this paper. As permissions were not granted to collect organisational performance data (e.g. sickness absence days, turnover) a cost benefits analysis of the intervention period was also not possible. 


\subsubsection{Evaluation interviews}

Since it was not possible to access data relating to individual health outcomes, qualitative improvements, such as raised awareness of occupational risks, improved communication within organisations (Laing et al., 2005) and the organisations' sense of ownership over the project (Rosecrance and Cook, 2005) were evaluated. This was achieved by conducting semi-structured interviews with the organisation champions in each of the remaining organisations. The aim of these interviews was to understand the factors which may have impacted the effectiveness of the intervention activities and the participatory process. The following were explored:

- changes to occupational health practices and policies

- cost-benefits of taking part in the project

- experiences of working with the research team

\subsubsection{Research diaries}

The researcher's diaries were used to identify and document the research team's interactions with the organisations. This included, detailed notes of all meetings, both face to face and via email / telephone. In addition, the researcher noted all the informal interactions with drivers, the organisation champion and other stakeholders. For example, at an early stage, the diaries indicated that these senior management teams (including the organisation champions) were previously unaware of drivers' use of their cars and the car based office activities undertaken by drivers. Also, managers in Organisations 2 and 3 were not aware that drivers were not taking test drives prior to selecting a car. They were also unaware that drivers were not making use of the seat adjustment training provided by the fleet delivery company. In addition, the management team in Organisation 3 had not been aware of the extent to which drivers were working from their cars.

As already indicated, the diaries were also an important element of the evaluation process. Specifically they highlighted the importance of the initial meetings with organisations and that these meetings essentially constituted the start of the intervention. They also enabled the capture of the informal interactions and discussions with participants as well as documenting the frequency and nature of interactions between the research team and the organisations. 


\section{Results}

The following sections provide the results of the study, beginning with the baseline data provided by the questionnaires. It is important to note that the initial meetings with organisations mark the start of the participatory process.

\subsection{The questionnaire survey (T1)}

This details of the questionnaire have been described elsewhere (the authors) and therefore the full results are beyond the scope of this paper. Instead, the findings which are most relevant to the co-development of the intervention are presented.

Briefly, respondents in all four organisations undertook work activities in their car during a typical day. This was most frequently mobile 'phone use, followed by eating lunch, paper work, and using a laptop. Across these organisations, 22\%-55\% reported 'sometimes' or 'often' working in their car (not driving) for 4 or more hours per day. Most of the questionnaire respondents reported that they were satisfied with the adjustable features of their car and their driving posture. With regard to musculoskeletal symptoms, in three of the organisations the most frequently reported area in the last 12 months was the low back (33\% to 57\%). However in Organisation 4 the most frequently reported areas were the neck and shoulders (31\% and 30\%). Low back trouble was also most frequently cited as affecting normal activities (11\% to 35\%) and as being related to their work (25\% to $53 \%)$. There was mixed 'acceptance' with regard to completing the psychosocial questions. Organisation 4 was not comfortable with these and so they were omitted from the questionnaire. For the other organisations (1, 2 and 3) job satisfaction was high. Organisational commitment was high and turnover intentions were low for Organisations 2 and 3 (Organisations 1 and 4 did not complete this section). However, psychological distress as measured by the GHQ was classed as 'fairly high' for organisations 1,2 and 3.

In three of the four organisations, the majority of drivers ( $70 \%$ or more) were 'pre-contemplative' in terms of the 'Stage of Change' assessment indicating that they were not considering the risks that their work posed to their musculoskeletal health. Within Organisation 4, 45\% of drivers were in the pre-contemplative stage and $47 \%$ were in the contemplative stage. Within the contemplative stage individuals are aware 
of the potential risks to their musculoskeletal health, but the advantages of continuing with a given (harmful) behaviour outweigh the disadvantages (Whysall et al., 2006a, $2006 \mathrm{~b}$ and 2007). The qualitative data from the interviews supported these findings.

\subsection{The participatory process}

\subsubsection{In-depth interviews}

The findings from the in-depth interviews have been published elsewhere (the authors) and as such the data which was used to co-develop the interventions is presented here.

From the interviews it became apparent that driver health was of concern. Within three of the organisations, business drivers were required to regularly undertake manual handling as part of their job, potentially exposing them to additional risk. Items handled from the vehicle included publicity materials, laptops and personal protective equipment. However, there was limited awareness amongst drivers of ergonomics and manual handling from a vehicle. A vehicle's suitability for work purposes was not considered when choosing company cars, rather, factors such as style, engine size, prestige, tax bracket and family needs were considered influential.

All of the organisations provided business drivers with training on how to use the adjustable features of their vehicle but most were sceptical about its value. This was particularly apparent within Organisation 4 where cars were provided to drivers as part of a benefits package rather than as work tool: '[company name] didn't force me to get the car so what does it have to do with them?' Within all of the organisations, those with responsibility for developing the training were also unsure of its uptake among business drivers. As a result both drivers and managers expressed a need for specific training in relation to working from the car. Those with responsibility for managing the occupational health of business drivers reported that the peripatetic nature of such employees made their job difficult. Specifically, meeting with drivers was hard to arrange as they were often working a considerable distance from the main office. In addition, time constraints and sales pressures meant that the drivers were often unwilling or unable to attend training sessions.

These in-depth interviews confirmed that the initial meetings with organisations were an important part of the participatory process. The organisation 'champions' had discussed the project and driving ergonomics in detail with their managers in order to 
secure agreement. In addition, similar conversations had taken place with line managers in order to ensure access to drivers. To this end, the researchers had already begun to affect change within the organisations.

Importantly these interviews enabled drivers and their managers to become involved in the participatory process. They suggested the nature of interventions, how they should be delivered (for example, the use of online training or face to face training) and how the research team and organisation champions could ensure uptake of interventions. These interviews were a key element of the participatory process as these hard to reach drivers were able to help shape the resulting interventions.

\subsubsection{Co-development of intervention activities}

As outlined in the methods section, the research team met with organisations and presented the findings from the questionnaire and interviews. These framed discussions for the co-development of intervention activities and were used to identify specific areas for the 'train the trainer' sessions where information/advice was needed. The online resource developed included the topics of:

- driver health

- driving posture

- risk management

- car selection

- working from the car

- training

- the cost-benefits of managing risk

The web resource also included a number of free downloadable advice sheets on car selection checklist (see Table 2), working from a car and manual handling. This resource was widely used by participating organisations. 


\section{Car selection checklist}

Test drive Yes

Have you test driven the car?

Did the test drive last for at least two hours?

\section{The seat}

Does the driver's seat have independent tilt adjustment?

Does the driver's seat have independent height adjustment?

Are the seat adjustment controls easy to use?

Are you able to reach the pedals without stretching?

Does the back rest reach your shoulders?

Does the back rest provide support along the length of your back?

Is your lumbar curve supported without any pressure points or gaps?

Do you have enough leg and head room?

Does the seat length put pressure on the back of your knee or calf?

Is the head restraint positioned close to your head?

Is the head restraint height near the top of your head?

Are you able to get in and out of the car easily?

\section{The steering wheel}

Is the steering wheel centrally located?

Does the steering wheel have the following adjustment features:

In/out?

Up/down?

Tilt?

Do you have full view of the display panel?

\section{The pedals}

Are the pedals centrally positioned?

Is there a left foot rest?

Is there plenty of room for you to rest your left foot?

\section{The boot}

Does the boot have space for you to store equipment or other items?

Does the boot have a low or flat sill height?

Does the boot have a narrow sill depth?

Does the boot have handles to facilitate closing?

Are you able to easily access your boot without obstruction, e.g. from the parcel shelf, or the boot lid itself? 
From the questionnaire, the majority of drivers in each organisation were 'precontemplative' and were not considering the potential risks to their musculoskeletal health posed by their work and were not taking steps to minimise that risk. Also, only a minority of drivers reported concern over how their working practices may impact their general health or their musculoskeletal health. Given this, the materials that were codeveloped were designed to raise driver awareness of how their working practices may affect their musculoskeletal health. For example, within three of the organisations a 'Working from the car' postcard was sent out to drivers (Figure 2a and Figure 2b). Since these drivers were not considering the impact of work on their musculoskeletal health, this postcard aimed to raise awareness among drivers of what constituted working from the car and provide details of sources of further information.

It is important to note that in addition to the intervention activities led by the research team, each organisation (led by the organisation champion) developed their own (Table 3) based on their specific needs.

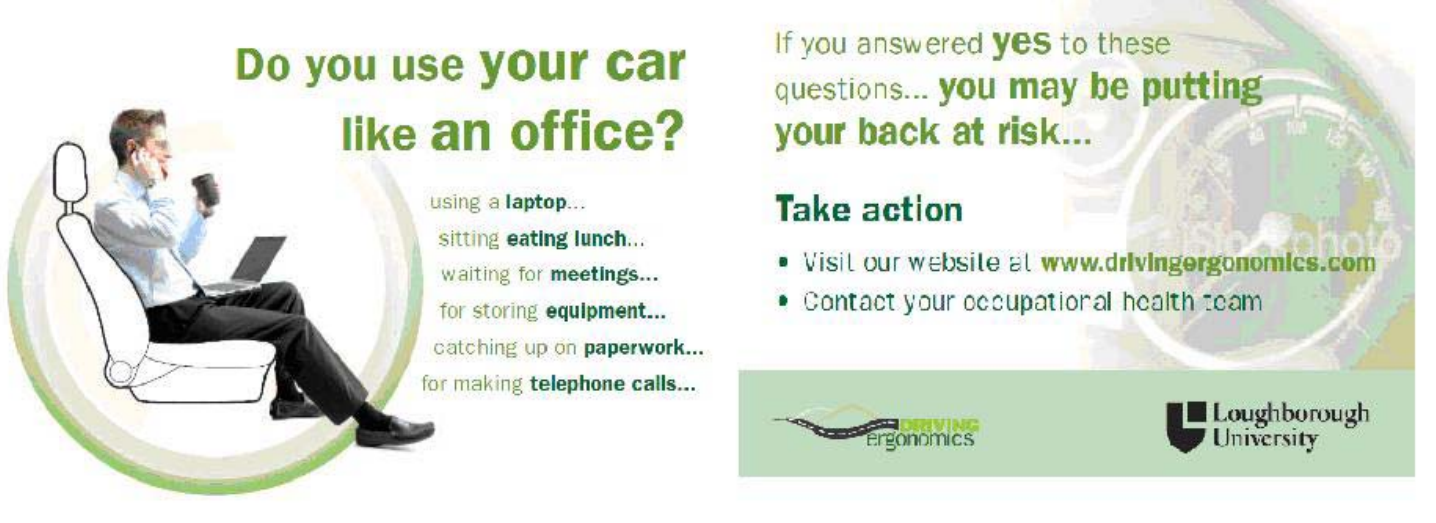

Figure $2 \mathrm{a}$ and Figure $2 \mathrm{~b}$. The 'Working from your car' postcard to raise driver awareness of working from the car. 
Table 3. Summary of the intervention activities within each organisation, both research team and organisation lead.

\begin{tabular}{|c|c|c|}
\hline Organisation & $\begin{array}{l}\text { Research team led activities / } \\
\text { materials }\end{array}$ & $\begin{array}{l}\text { Organisation led activities / } \\
\text { materials }\end{array}$ \\
\hline $\begin{array}{l}\text { 1. Multinational manufacturing } \\
\text { company }\end{array}$ & $\begin{array}{l}6 \text { tailored 'train-the-trainer' sessions } \\
\text { Raising awareness - distribution of } \\
\text { postcard } \\
\text { Regular email and telephone support }\end{array}$ & $\begin{array}{l}\text { Distribution of 'Driving Ergonomics' } \\
\text { newsletter to all drivers, based on website material. } \\
\text { Discussion of policy changes to car list. }\end{array}$ \\
\hline $\begin{array}{l}\text { 2. UK based utilities } \\
\text { organisation }\end{array}$ & $\begin{array}{l}4 \text { tailored 'train-the-trainer' sessions } \\
\text { Raising awareness - distribution of } \\
\text { postcard } \\
\text { Regular email and telephone support }\end{array}$ & $\begin{array}{l}\text { Fleet manager to request training on } \\
\text { the use of adjustable features of } \\
\text { company cars }\end{array}$ \\
\hline $\begin{array}{l}\text { 3. Multinational pharmaceutical } \\
\text { company }\end{array}$ & $\begin{array}{l}3 \text { tailored 'train-the-trainer' sessions } \\
\text { Raising awareness - distribution of } \\
\text { postcard } \\
\text { Regular email and telephone support }\end{array}$ & $\begin{array}{l}\text { Development of 'pre-contemplative' } \\
\text { training materials (for new employees) using based on } \\
\text { website material: } \\
\text { 1. Power point presentation on setting } \\
\text { up the car and working from the car } \\
\text { 2. Driving ergonomics DVD }\end{array}$ \\
\hline 4. Multinational consultancy & $\begin{array}{l}2 \text { tailored 'train-the-trainer' sessions } \\
\text { Regular email and telephone support }\end{array}$ & $\begin{array}{l}\text { Development of bespoke } \\
\text { 'Working from the car' postcard based on } \\
\text { website material } \\
\text { Changes to Fleet Services Intranet }\end{array}$ \\
\hline
\end{tabular}




\subsection{Evaluating the participatory process}

\subsubsection{Questionnaire survey (T2)}

As stated previously, it was not possible to fully evaluate the intervention process through the questionnaire survey (at T1 and T2). However, comparing findings from the questionnaire survey, working from the car remained an issue for drivers in these organisations. Some reduction could be seen in work activities in the car, particularly with eating lunch, writing and laptop use but mobile phone use remained constant. However, there was an increase in the percentage of participants reporting manual handling, undertaking standing and sitting tasks for 4 or more hours per day. Respondents across organisations were again generally satisfied with the ease of use of the adjustable features of their vehicles. There was also an increase in the percentage of respondents reporting satisfaction with the posture they were able to achieve in the car.

There were a number of changes in the percentage of respondents reporting musculoskeletal symptoms. There was a small increase in 12 month reported prevalence of symptoms in the low back, knees and shoulders in Organisation 2 and the neck and shoulders in Organisation 4. Period prevalence of low back trouble remained constant within Organisations 3 and 4, but showed an increase in Organisation 2. A similar pattern emerges with 7 day point prevalence and severity of musculoskeletal symptoms in Organisations 3 and 4. It was disappointing that the questionnaire indicated that few of these 'driver' respondents were aware of the online resource but the majority of those who had seen the materials rated them as either 'useful' or 'very useful'.

\subsubsection{In-depth interviews}

The interviewees described the 'organisation led activities/materials' which had taken place during the project as opposed to those led by the research team (Table 3). The organisation champions for Organisations 2 and 3 were keen to continue the work started by this project. Specifically, in Organisation 2 it was planned to use the codeveloped materials to form an information pack which could be distributed to all drivers through their Dealership Management Contractor. The intention was that all drivers would receive this information at the handover of their next company car. 
Within Organisation 3 it was planned to use the material to inform occupational health policy and practice, for example, rolling out training to all drivers not just new starters. This positive feedback from the organisations suggests that the participatory process was effective in engaging key stakeholders. Specifically, key stakeholders in two of the organisations showed a commitment to continuing efforts to work with business drivers to minimise the impact on musculoskeletal health. It is evident that within Organisations 2 and 3 the senior management teams had become aware of the potentially serious risks to their driving population and were making efforts to develop long term plans to address these. As such, managers became more aware not only of the extent which drivers were working in their cars, but also of their organisations role in minimising risks. This increased awareness which resulted from the project, in addition to existing concerns about drivers' occupational health (as evidenced by participating in the project) appear to have resulted in a commitment to continuing with the co-developed interventions.

These interviews revealed that calculating the cost-benefits of participating in the project was problematic. All respondents reported that they were not able to secure access to the necessary information, for example, reportable sickness absence or costs of recruiting new staff. The costs of taking part in the research had been absorbed by existing budgets and the in-house production of training materials meant that associated costs were impossible to quantify.

All interviewees reported the frustrations of being in large organisations and the resulting delays in changing internal policies and procedures. Two organisations experienced changes in personnel, specifically, the champions in Organisations 2 and 3 changed employers. This resulted in poor internal communications and caused delays in the development and implementation of the planned initiatives. Finally, one interviewee also highlighted the difficulty communicating with a disparate group like 'high mileage drivers' and the lack of internal mechanisms for distribution of information.

\subsubsection{Researcher diaries}

Reflections taken from the research diaries suggests that the 'train the trainer' sessions, provided by the research team, were well received. For example, in Organisation 1 positive feedback was received from both from business drivers and 
their managers who were keen to learn about ergonomics issues such as seat adjustment and manual handling. The sessions also provided an opportunity for them to share experiences and information with other drivers, which is perhaps not surprising as business driving is essentially an isolated occupation. Previous projects have also identified the importance of group meetings where drivers can share experiences and encourage changes to attitudes (Carlise and Baden-Fuller, 2004). Some drivers in all organisations expressed resistance to suggestions by the research team for example, the need to take regular breaks and choose cars which were appropriate to their job. However, drivers who had suffered back problems (for example) were able to describe their experiences and their enthusiasm for the training was helpful in encouraging change in other drivers.

The diaries also demonstrated the importance of the organisation champions to the project. They initiated the research team's access to the senior organisation stakeholders to approve participation in the project and were key to facilitating all stages of the research, for example sending out the questionnaire, facilitating the 'trainthe-trainer' sessions, and identifying key stakeholders for implementing the codeveloped activities. The champion's position as a senior manager within their organisation meant that they were able to influence drivers and their managers. For example, within Organisation 1 drivers and their managers reported (detailed in the research diaries) that their participation in the project was secured by what they referred to as the charisma and drive of the organisation champion. However, the diaries also reveal that the central importance of these champions can add to the vulnerability of such projects. Within 3 of the 4 organisations, the champion either left the organisation or their role was drastically changed. The diaries revealed that this resulted in significant delays in the project moving forward while new champions were identified within the organisation.

\section{Discussion}

There is evidence consistent with the literature that business drivers engage in a range of activities which are known to pose risks to musculoskeletal health (Porter and Gyi, 2002; Sakakibara et al., 2006; Sang et al., 2010a). Specifically, drivers reported high mileage, working from their car and manual handling. Initially, the majority of business drivers were in the 'pre-contemplative' stage meaning that they were not considering 
modifying their behaviour at work to reduce the risk of MSDs (Whysall et al., 2006a, 2006b, 2007). The intervention activities were therefore tailored to raise awareness amongst business drivers of the risks posed to their musculoskeletal health. The materials co-developed from these activities were included in an online driving ergonomics resource freely available to all organisations. Evidence from previous research has shown that interventions aimed at providing information and support can be effective in reducing sickness absence from work (McCluskey et al., 2006). In addition, the participatory process has been proposed as method of enhancing the efficacy of interventions designed to reduce musculoskeletal discomfort (Ketola et al., 2002). The direct involvement of employees in the design and development of changes to their workplace is thought to increase receptiveness change (Nagamachi, 1995).

It was originally proposed that the success of the participatory process would be evaluated in terms of individual health benefits, organisational performance and a reduction to the costs of ill health. Due to participant attrition through redundancies which was unavoidable in the context of the global economic crisis, it was not possible to compare the questionnaire findings from T1 and T2 (Figure 1). This situation has been faced by other researchers, who due to participant attrition have not been able to undertake post intervention statistical analysis (Torma-Krajewski, et al., 2007). As permissions were not granted to collect organisational performance data (e.g. sickness absence days, turnover), nor were these data easily available, a cost benefits analysis of the intervention period was also not possible. However, the success of a participatory approach can be assessed through examination of qualitative improvements, for example, raised awareness of issues and improved communication between workers and managers (Laing et al., 2005). In the absence of reliable quantitative data, the research diaries proved to be an invaluable tool for assessing the effectiveness of the intervention activities. These diaries enabled the researcher to record not only the frequency and content of interactions with the organisations, but also reflections on the process. The diaries were able to capture these 'softer' aspects of the project, for example, informal conversations with drivers themselves, their managers and the organisation champions.

One key feature of a successful participatory ergonomics intervention is a sense of ownership within the participating organisation (Rosecrance and Cook, 2000). All of the organisations had developed (and were continuing to develop) their own way forward as a result of their association with the project (Table 3). Haims and Carayon (1998) have argued that a participatory approach is beneficial in improving 
communication between workers and their managers and this may have been the case with the current project. This benefit is particularly important when dealing with a peripatetic workforce with infrequent contact with line managers and occupational health facilities.

A key observation is that the research team had begun to affect change at the managerial level from its first contacts with organisations. The value of these initial contacts and meetings has been alluded to in previous studies which have developed ergonomics committees (e.g. Rosecrance and Cook, 2000). The current study differs in that it is apparent that the impact of the intervention activities and online resource cannot be discussed in isolation from the effect the research team had on the management of the organisation. Therefore the intervention start date was deemed to be the date of the first face to face meeting between the research team and the organisation champions. Previous research which has drawn clear distinction between the initial phase of participatory interventions and the 'active' interventions (e.g. Rosecrance and Cook, 2000; Rivilis et al., 2006) may be failing to take into account the impact of this. Our research suggests that the recruitment phase of a participatory project is important not only in securing access to participants, but should also be considered part of the intervention process and therefore well-documented.

Organisational structures meant that the time taken to gain 'permissions' was considerably greater than anticipated as a number of committees and high level individuals had to give approvals at each stage of the project. Securing such agreement is essential for the success of an intervention (Polanyi et al., 2005). However, this process of gaining approval also resulted in early dissemination of the project and of driving ergonomics. It is proposed that the main impact of the research is seen at the managerial level where efforts were being made to effect change. This is a key output of the study and demonstrates that a participatory approach can be beneficial in gaining and solidifying management commitment to reducing risk (Burgess-Limerick et al., 2007).

Participant attrition occurred across all organisations, despite considerable efforts on the part of the research team: this has also been noted by other researchers (Breakwell et al., 2006). As a result, a comparatively small numbers of participants completed the post-intervention questionnaire and renders comparative analysis of health benefits limited. A cross sectional approach was therefore taken, whereby data were compared at two time points (T1 and T2, see Figure 1). An apparent increase in 
reporting of musculoskeletal symptoms in Organisations 2 and 4 could be the result of an increased awareness of the issue. Kee and Seo (2007) have suggested that better awareness can lead to increased reporting. Similar participatory projects have also 'failed' to demonstrate any significant or systematic reduction in musculoskeletal symptoms (Laing et al., 2005). There was also an apparent increase in the percentage of respondents reporting manual handling and standing tasks for 4 or more hours per day. Again it is likely that drivers were more aware of the manual handling they routinely do from the vehicle. A general increase in reported satisfaction with the adjustable features of their vehicle was also found. Few respondents had purchased new company cars during this period, so drivers could also have become more familiar with them.

The aim of the train-the-trainer sessions was to encourage awareness of the risks to musculoskeletal health of the day to day activities of drivers in their vehicles, specifically, the potential harm caused by using the car as an office and manual handling from the car. Additionally, the intervention activities were designed in order to make drivers more aware of ergonomics issues when choosing their company car. In other words, the intervention was intended to foster a change of attitudes amongst business drivers. Carlisle and Baden-Fuller (2004) have highlighted some of the problems encountered when attempting to change the attitudes of individuals who drive as part of their job. Their study of oil transportation workers identified the solitary nature of the work and the necessity of group meetings for drivers if changes in attitudes are to be achieved. During these meetings they observed that drivers who were less convinced of the benefits of change were influenced by more enthusiastic colleagues. Similar effects were observed in the current study. As such, future researchers should consider this when designing training, for example, the inclusion of a more experienced driver who can share their experiences and perhaps influence behaviours.

Over the project, the implementation and evaluation of intervention activities (supported by the online resource) did pose challenges for a number of reasons, including, a downturn in the UK economy resulting participant attrition, personnel changes, changes in organisation structure and the nature of business drivers' work. Longitudinal organisation research is vulnerable to such issues which are outside the control of the researcher (Ivancevich and Matterson, 1978). For example, Organisation 1 was badly affected by changes in the economy, resulting driver redundancies and the organisation champion losing her strategic role towards the end of the project. Laing et al (2007) reflect that a committed organisation champion may result in more 'successful' 
participatory interventions. As stated previously, these organisation champions were essential to progress each stage of the current project. However, many of the difficulties experienced within the project were beyond the control of the research team. During the post intervention interviews Organisation 3 reported insufficient communication between the research team and the organisation champion. This was problematic as they were on sick leave and then left the organisation shortly after the start of the project and were not replaced for more than 12 months. Given that the organisation champion in all four of the organisations either left or changed their responsibilities, future studies may want to consider having two champions or a secondary contact who can maintain continuity.

According to the post intervention questionnaire data, few drivers reported being aware of the online resource and the training materials which had been co-developed by the research team and the organisation champions. This is perhaps not surprising, for example in Organisation 3 the training materials were only available to new drivers as part of their induction. This highlights another concern, in that the participating organisation may not implement the intervention as suggested by the research team (McCluskey et al., 2006).

The current study has a number of implications for future research and organisational policy makers. Firstly, future researchers should consider follow up studies of participatory processes. The participating organisations in the current study were able to claim ownership of the interventions, but due to budgetary constraints it was not possible to follow up with the organisations after the completion of the project. Ideally, future studies should examine the long term sustainability of such interventions. However, it is important to remember the difficulties associated with longitudinal field work within organisations, as outlined earlier in the paper, namely, the impact of external changes such as economic instability, and internal changes including staff turnover. As the data suggests here, drivers were resistant to some of the suggested behavioural changes proposed by the research team. Further work is needed to understand the nature of such tensions and to determine appropriate ways of overcoming these problems. However, the research diaries do suggest that a participatory approach may an effective method of influencing health behaviours. Additionally, there are policy level implications for researchers and those with responsibilities for managing the occupational health of drivers. For example, 
researchers and organisations could work together to co-develop policies regarding compulsory test drives and training on the adjustable features of the car.

\section{Conclusions}

The participatory approach raised management awareness of musculoskeletal symptoms amongst business drivers and the project was successful in affecting change at the management level facilitated by the web resource. Organisations felt sufficient ownership of the project to be able to develop their own solutions to the identified problems, in conjunction with support from the research team.

When undertaking research of this nature, the length of time taken to secure 'permissions' should be considered. This is particularly important when working with large organisations as they often require consent from a range of departments/sectors/committees before research can proceed. Researchers should consider this phase as part of the intervention process, particularly when evaluating the impact at the managerial level.

Longitudinal research in the field is vulnerable to a range of factors which are beyond the control of the researchers. Care should be taken to ensure that the research design and methodology is flexible and can adapt to risks such as changes to key personnel, internal politics, organisational structures and the global economics.

\section{References}

Basri, B. and Griffin, M. J. 2012. Equivalent comfort contours for vertical seat vibration: effect of vibration magnitude and backrest inclination. Ergonomics 55(8): 909-922.

Brown, O., 2002. Macroergonomic methods: participation. In: H.W. Hendrick, and B.M. Kleiner, eds, Ergonomics, Theory, Methods and Applications. Mahwah, NJ: Lawrence Erlbaum Associates, 25-44.

Buckland, R., 2009. Private and Public Sector Models for Strategies in Universities. British Journal of Management, 20 (4), 524-536.

Burgess-Limerick R., Straker, L., Pollock, C., Dennis, G., Leveritt S. and Johnson, S., 2007. Implementation of the Participative Ergonomics for Manual tasks (PErforM) programme at four Australian underground coal mines. International Journal of Industrial Ergonomics, 37(2), 145-155. 
Cammann, C., Fichman, M., Jenkins JR, G.D. and Klesh, J.R., 1983. Assessing the attitudes and perceptions of organizational members. In: S. Seashore, E. Lawler, P.Mirvis and C. Cammann, eds, Assessing Organizational Change: A Guide to Methods, Measures and Practices. New York: John Wiley, 71-138.

Eisenberger, R., Huntington, R., Hutchinson, S. and Sowa, D., 1986. Perceived organizational support. Journal of Applied Psychology, 71 (3), 500-507.

Flyte, M.G., 2000. The vehicle as an IT office environment: ergonomics design requirements for mobile computing. International Journal of Vehicle Design, 23(3/4), 329-341.

Gjessing, C.C., Schoenborn, T.F. and Cohen, A., 1994. Participatory Ergonomic Interventions in Meat Packing Plants. Cincinatti, Ohio: NIOSH.

Goldberg, D., 1972. The Detection of Psychiatric Illness by Questionnaire: A Technique for the Identification and Assessment of Non-psychotic Psychiatric Illness. London: Maudsley Monographs.

Haims, M.C. and Carayon, P., 1998. Theory and practice for the implementation of 'inhouse' continuous improvement participatory ergonomics programs. Applied Ergonomics, 29 (6), 461-472.

Harris G. and Mayhog, L., 2003. Occupational health issues affecting the pharmaceutical sales force. Occupational Medicine, 53 (6), 378-383.

Haslam, S. A., Eggins, R. A., and Reynolds, K. J., 2003. The ASPIRe model:

Actualizing Social and Personal Identity Resources to enhance organizational outcomes. Journal of Occupational and Organizational Psychology 76, 83-113.

Haslam, C., Clemes, S., McDermott, H., Shaw, K., Williams, C. and Haslam, R., 2007. Manual handling training: Investigation of current practices and development of guidelines, RR583. Sudbury, Suffolk: HSE Books.

HSE, 2010. Health and Safety Executive Statistics, 2009/10. Available from: http://www.hse.gov.uk/statistics/overall/hssh0910.pdf (Accessed 1 August 2011).

Hess, J.A., Hecker S., Weinstein, M., and Lunger, 2004. A participatory ergonomics intervention to reduce risk factors for low-back disorders in concrete laborers. Applied Ergonomics, 35 (5), 427-41.

Hignett, S., 2003. Intervention strategies to reduce musculoskeletal injuries associated with handling patients: a systematic review. Occupational and Environmental Medicine, 60 (9). Available from: //oem.bmjournals.com/cgi/reprint/60/69/e66.pdf (Accessed 1 August 2011).

Israel, B.A., Schurman, S.J. and Hugentobler, M.K., 1992. Conducting action research: Relationships between organization members and researchers. Journal of Applied Behavioral Science, 28, 74-101.

Kee, D. and Seo, S.R., 2007. Musculoskeletal disorders among nursing personnel in Korea. International Journal of Industrial Ergonomics, 37 (3), 207-212. 
Ketola, R., Toivonen, R., Hakkanen, M., Luukkonen, R., Takala, E. and Viikari-juntura, E., 2002. Effects of ergonomic intervention in work with video display units. Scandinavian Journal of Work, Environment and Health, 28 (1), 18-24.

King, N., 2004. Using templates in the Thematic Analysis of Text. In: C. Cassell and G. Symon, eds, Essential Guide to Qualitative Methods in Organizational Research. London: Sage Publications, 256-270.

Kourinka, I., Jonsson, B. and Kilbom, A.E.A., 1987. Nordic questionnaires for the analysis of musculoskeletal symptoms. Applied Ergonomics, 18 (3), 233-237.

Laing, A.C., Cole, D.C., Theberge, N., Wells, R.P., Kerr, M.S. and Frazer, M.B., 2007. Effectiveness of a participatory ergonomics intervention in improving communication and psychosocial exposures. Ergonomics, 50 (7), 1092-1109.

Macaulay, A. C., Commanda, L. E., Freeman, W. L., Gibson, N., McCabe, M. L., Robbins, C. M.,et al., 1999. Participatory research maximizes community and lay involvement. British Medical Journal, 319 (7212), 774-778.

McCluskey, S., Burton, A.K. and Main, C.J., 2006. The implementation of occupational health guidelines principles for reducing sickness absence due to musculoskeletal disorders. Occupational Medicine, 56 (4), 237-242.

Nagamachi, M., 1995. Requisites and practices of participatory ergonomics. International Journal of Industrial Ergonomics, 15 (5), 371-377.

Polanyi, M.F., Cole, D.C., Ferrier, S.E. and Facey, M., 2005. Paddling upstream: a contextual analysis of implementation of a workplace ergonomic policy at a large newspaper. Applied Ergonomics, 36 (2), 231-239.

Porter, J.M. and Gyi, D.E., 2002. The prevalence of musculoskeletal troubles among car drivers. Occupational Medicine, 52 (1), 4-12.

Prochaska, J.M., Prochaska, J.O. and Levesque, D.A., 2001. A transtheoretical approach to changing organizations. Administration and Policy in Mental Health, 28 (4), 247261.

Reason, P., 1994. Three approaches to participative inquiry. In: N.K. Denzin and Y.S. Lincoln, eds, Handbook of Qualitative Research.

http://www.peterreason.eu/Participationinhumaninquiry/Contents list.html Thousand Oaks: Sage Publications. 324-339.

Rivilis, I., Van Eerd, D., Cullen, K., Cole, D.C., Irvin, E., Tyson, J. and Mahood, Q., 2008. Effectiveness of participatory ergonomic interventions in health outcomes: a systematic review. Applied Ergonomics, 39 (3), 342-358.

Rosecrance, J.C. and Cook, T.M., 2000. The use of participatory action research and ergonomics in the preventions of work-related musculoskeletal disorders in the newspaper industry. Applied Occupational and Environmental Hygiene, 15 (3), 255262. 
Sakakibara, T., Kasai, Y. and Uchida, A., 2006. Effects of driving on low back pain. Occupational Medicine, 56 (7), 494-496.

Sang, K.J.C., Gyi, D.E. and Haslam, C.O., 2010a. Musculoskeletal symptoms in pharmaceutical sales representatives. Occupational Medicine. 60 (2). 108-114.

Sang, K.J.C., Gyi, D.E. and Haslam, C.O., 2010b. Stakeholder perspectives on managing the occupational health of UK business drivers: A qualitative approach. Applied Ergonomics, 42 (3), 419-425.

Torma-Krawjewski, J., Steiner, L., Lewis, P., Gust, P., and Johnson, K., 2007. Implementation of an ergonomics process at a US surface coal mine. International Journal of Industrial Ergonomics 37 (2), 157-167.

Van, Eerd, D., Cole, D., Irvin, E., Mahood, Q., Keown, K.,M Theberge, N., Village, J., St. Vincent, M., and Cullen, K., 2010. Process and implementation of participatory ergonomic interventions: a systematic review. Ergonomics 53 (10), 1153-1166.

Whysall, Z., Haslam, C. and Haslam, R., 2005. A staged approach to reducing musculoskeletal disorders (MSDs) in the workplace. RR379. Sudbury, Suffolk.: HSE Books.

Whysall, Z., Haslam, C. and Haslam, R., 2006a. A stage of change approach to reducing occupational ill health. Preventative Medicine, 43 (5), 422-428.

Whysall, Z., Haslam, C. and Haslam, R., 2006b. Implementing health and safety interventions in the workplace: An exploratory study. International Journal of Industrial Ergonomics, 36 (9), 809-818.

Whysall, Z., Haslam, C. and Haslam, R., 2007. Developing the stage of change approach for the reduction of work-related musculoskeletal disorders. Journal of Health Psychology, 12 (1), 184-197.

Wilson, J.E., 1995. Solution ownership in participative work design: The case of a crane control room. International Journal of Industrial Ergonomics, 15 (5), 329-344. 
